\title{
Internação compulsória de pessoas em uso de drogas e a Contrarreforma Psiquiátrica Brasileira
}

\section{| ${ }^{1}$ Américo Orlando Azevedo, ${ }^{2}$ Tadeu de Paula Souza |}

Resumo: Este artigo desenvolve uma reflexão crítica ao atual movimento ligado às iniciativas de Internação Compulsória (IC) como abordagem e proposta de tratamento às pessoas em uso de drogas, em um contexto de novos desafios que se apresentam à continuidade da Reforma Psiquiátrica Brasileira (RP). Analisamos o dispositivo da IC enquanto produtor de regimes de visibilidade, percebendo que a sua prática e legitimação com a população usuária de crack estão associadas a elementos de atualização de movimentos históricos presentes desde o século XIX, conforme apresentado por Foucault, movimentos esses de articulação entre os poderes jurídico e médico, produzindo práticas que se legitimam através da apropriação dessa população como o novo sujeito Anormal sobre o qual se pretende intervir. Essa manobra abre também brechas para utilização de mecanismos referentes à $\mathrm{IC}$ presentes na lei da RP desvinculados de outros termos, principalmente os que buscam preservar e sustentar os direitos das pessoas que são assistidas pelas políticas de saúde mental, contrariando os aspectos progressistas contidos em sua origem. Consideramos as iniciativas de intensificação dos processos de IC expressões de ação do biopoder, com relevância na produção de políticas e de subjetividades contemporâneas de resistência à continuidade e ampliação da Reforma Psiquiátrica Brasileira.

> Palavras-chave: saúde mental; internação compulsória; serviços de saúde mental; Reforma Psiquiátrica Brasileira.

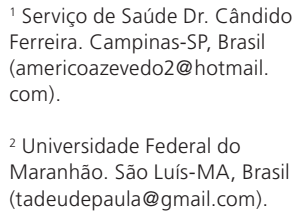

1 Serviço de Saúde Dr. Cândido Ferreira. Campinas-SP, Brasil (americoazevedo2@hotmail. com).

${ }^{2}$ Universidade Federal do Maranhão. São Luís-MA, Brasil (tadeudepaula@gmail.com).

Recebido em: 18/10/2016 Aprovado em: 30/05/2017 


\section{Introdução}

Este artigo desenvolve uma reflexão crítica em relação ao movimento médicojudicial ligado às iniciativas de Internação Compulsória (IC) como estratégia e solução para o problema dos usuários de crack em situação de rua, em um contexto de novos desafios que se apresentam à continuidade da Reforma Psiquiátrica Brasileira (RPB).

Para isso, a apresentação e análise do movimento da IC se darão a partir do conceito de dispositivo, a IC enquanto uma "máquina de fazer ver e fazer falar", que produz regimes de visibilidade e dizibilidade (FOUCAULT, 1977, 1986; DELEUZE, 1988, 1996) sobre os usuários de drogas. Foucault (1986) nomeia dispositivo um conjunto heterogêneo de elementos, como lei, normas, organizações arquitetônicas, saberes e poderes que respondem a uma urgência. Essa urgência corresponde a uma ordem social ampla e geral, como esquadrinhar o espaço urbano, disciplinar os corpos, fazer viver o homem enquanto espécie. Um dispositivo agencia uma rede de elementos visíveis e dizíveis que compóe uma rede ou diagrama de saber-poder (DELEUZE 1988, 1996)

Utilizamos o conceito de dispositivo (FOUCAULT, 1977, 1986) para tentar compreender como a IC busca se instituir como uma prática legítima para uma demanda de saúde, mesmo que seja fracassada sua eficácia enquanto abordagem de tratamento. Interessa, portanto, entender quais regimes de saber-poder, discursivos e não discursivos à IC, vêm produzindo sobre as pessoas que fazem uso de drogas, a partir do fenômeno contemporâneo do crack na sociedade brasileira.

O empreendimento deste trabalho necessita articular reflexões acerca do atual contexto brasileiro, sem igualá-lo ao período europeu dos séculos XVIII e XIX utilizados na análise do autor, mas valendo-se dessa análise e dos conceitos daí produzidos por Foucault para lançar luz ao fenômeno da IC na sociedade brasileira contemporânea (RAUTER, 2003).

A novidade aqui explorada evidentemente não se refere ao dispositivo da IC em si, visto que este nada tem de novo. Mas às condiçôes de possibilidade de reedição deste dispositivo no contexto atual brasileiro. A que ele vem responder? Que regimes de visibilidade e dizibilidade ele agencia? Que diagrama de saberpoder ele põe a funcionar? Qual sua função estratégica atual no Brasil? A que movimento mais amplo a IC se agencia? 
Cabe reforçar que tais análises se situam em referência ao movimento da RPB. Que função estratégica a RPB conferiu a IC e que modulação observamos a partir do fenômeno crack?

Para o entendimento desse momento, da força dessas políticas e abordagens, ligadas a ações involuntárias e ou compulsórias no Brasil, é importante situá-lo no movimento histórico da Guerra às Drogas e de seu impacto enquanto ideologia proibicionista hegemônica, na abordagem da questão das drogas.

\section{$\mathrm{RPB}$ e a geopolítica da guerra às drogas}

Adotamos o termo 'geopolítica das drogas' em referência à pesquisa de Labrousse (2010), que mostra como a política mundial de guerra às drogas se atualiza de modo muito singular em diferentes países do mundo. Desse modo, a geopolítica da guerra às drogas deve ser vista como uma importante faceta da expansão de uma nova modalidade de poder que agencia elementos militares, econômicos, diplomáticos, bem como de propagação de aspectos morais e legais que determinam as bases de ação em nível global (RODRIGUES, 2012). Logo, trata-se de uma análise estratégica que não pretende extrair da guerra às drogas um modelo universal de análise. Interessa compreender alguns aspectos dessa política no Ocidente e seus efeitos na política de saúde no Brasil.

De certa forma, grande parte do sucesso dessa empreitada e de sua força, desde os anos 1980, está ligada à substituição dos elementos de ameaça à democracia e à liberdade, antes atribuídos ao comunismo, pelas drogas e pelo terrorismo. A "guerra às drogas" e a "guerra ao terrorismo" trouxeram um novo sentido para o conceito de guerra. O ciclo global de guerras torna cada vez mais impreciso a distinção entre conflitos externos e segurança interna. "O 'inimigo', que tradicionalmente era enxergado fora, e as 'classes perigosas', que tradicionalmente se encontravam dentro, tornam-se cada vez mais difícil de distinguir, servindo conjuntamente como objeto do esforço de guerra" (HARDT; NEGRI, 2005, p. 36). A aposta na guerra como forma de manter a ordem social acaba por fazer da guerra um estado contínuo ao invés de um estado de exceção. "Em outras palavras, não é possível vencer uma guerra dessas, ou, por outra, ela deve ser vencida diariamente. Assim é que se tornou impossível distinguir a guerra da atividade policial” (HARDT; NEGRI, 2005, p. 36). 
A rede de criminalização das drogas criou um circuito discursivo vicioso e hermético em que o usuário de drogas, embora um "doente”, passa a ser também o responsável pelo tráfico, um agente promotor do tráfico de drogas, logo, um agente da rede criminosa. Gerou-se uma imagem estereotipada do usuário, como aquele responsável pelo fortalecimento do tráfico de drogas ilícitas e, consequentemente, uma bizarra situação de uma doença ilícita. Mas não foi suficiente somente uma associação entre drogas e tráfico ilegal, era necessário constituir um regime de verdade sobre o usuário de drogas que apontasse, a partir do dependente químico e em grave situação de saúde, o destino de todos os usuários de drogas. Uma imagem que mobilizasse toda a sociedade para o combate às drogas, um regime de visibilidade que traduzisse ou expressasse uma verdade sobre as drogas.

Embora, no mundo capitalista, haja uma multiplicação e proliferação do uso de drogas, lícitas e ilícitas, produziu-se, a partir do proibicionismo, uma redução desse campo perceptivo sobre o fenômeno das drogas, através da polarização lícito e ilícito e suas inevitáveis contradições. Foi, portanto, nesse novo regime de visibilidade que, a partir da segunda metade do século XX, observou-se que a abstinência foi, através de um conjunto de elementos, deixando de ser somente uma norma moral religiosa, da castidade em relação aos prazeres da carne, para se tornar a um só tempo uma lei e uma diretriz clínico-psiquiátrica, como expressa na Lei de Entorpecentes 6.368, de 1976 (PASSOS; SOUZA, 2011). Ao usuário de drogas cabe a pena de tratar-se para tornar-se abstinente. Sendo que a própria psiquiatria definiu a dependência química como uma doença crônica incurável.

A influência desse regime de verdade, centralizada nas propostas e abordagens ligadas à abstenção do uso de drogas, produziu grande impacto nas políticas de saúde no Brasil. São objetivos das intervençôes terapêuticas, buscando efetivar-se como diretrizes dos sistemas de saúde, em que a lógica da abstinência tem sido uma lógica de tratamento aliada ao ideal de um mundo livre das drogas. Ao estigmatizar o usuário de drogas enquanto um criminoso, seu lugar na saúde se dá de dois modos, ou compulsoriamente ou na condição de quem deseja parar de usar drogas. Desse modo, os serviços de saúde tendem a acolher esse usuário somente quando a situação já se agravou bastante: uma rede de produção da situação aguda. E aos usuários que não desejam parar de usar drogas restam duas opções: a exclusão ou o uso da força. Vem à tona, também, tensões relativas 
à forma como a sociedade contemporânea lê e fala sobre a experiência com as drogas lícitas e ilícitas, na qual o usuário é convocado a falar desde o lugar de arrependido e comprometido a parar de usar drogas (TEDESCO; SOUZA, 2009; SOUZA; CARVALHO, 2012).

A abstinência se configura, assim, num agenciador do regime discursivo que sustenta a necessidade de Internação Compulsória. Entretanto, isso precisou ser feito de tal modo que essa exigência não compareça como uma exceção, mas como uma regra. Para isso, foi necessário construir um regime de visibilidade que expressasse, a partir dos usuários de drogas em situação grave, uma verdade sobre as drogas: um regime de luz sobre o destino para aqueles que se arriscarem a experimentar as drogas.

Os efeitos da 'guerra às drogas' sobre a saúde pública se tornam duplamente danosos: uma vez que excluem e estigmatizam o usuário de drogas e propõem, como modo de reaproximá-lo, medidas impositivas. Essa política hegemônica produziu grandes impactos contraditórios, do ponto de vista ético, legal e social, ao longo de sua expansão e definição como forma única de lidar com essa problemática. Gradativamente, tem havido esforços em outros sentidos ${ }^{1}$ na abordagem atualmente da questão das drogas no mundo.

\section{Crack e os novos anormais}

Acreditamos ser essa a questão de maior relevância no cenário atual, saber qual a função de se adotar a IC como metodologia de abordagem e tratamento das pessoas em uso de álcool, crack e outras drogas, face ao que se busca oferecendo tal intervenção.

Conforme indica o levantamento realizado por Duailibi (2010), o surgimento do crack ocorreu na metade da década de 1980, nos Estados Unidos, dando-se depois sua consequente chegada a outros países, com aumento significativo de seu uso e sua produção sempre associados ao consumo nos centros urbanos e periferias das grandes cidades.

No caso do Brasil, indica a autora, a disseminação do uso teve aumento importante na década de 1990, estando relacionada com as populações mais vulneráveis - característica observável do crack desde seu surgimento -, atingindo também outros grupos após sua popularização e facilidade de acesso. 
Evidentemente, o retorno das medidas de IC enquanto política pública tem sua relação com o atual panorama do uso do crack pelas populações em situação de rua e cria um novo agenciamento para estes territórios, uma vez que passam a compor a rede econômica do tráfico de drogas ilícitas. O crack, como elemento agregador da população em situação de rua, gerou grandes concentraçōes denominadas de "cracolândias". Trata-se de entender como que, a partir do fenômeno do crack, foi possível constituir um novo regime de visibilidade que expressa a emergência por intervenções autoritárias.

Para compreender tal fenômeno, recorremos ao pensamento de Foucault sobre a aproximação entre justiça e psiquiatria na construção das sociedades de normalização e na ampliação e intensificação do biopoder e suas implicações no contexto brasileiro. Foucault $(2001,2008)$ trata de uma reconstrução do conceito de 'anormal', resultante de embates e conexões dos saberes jurídico e psiquiátrico analisados a partir do dispositivo do exame psiquiátrico de imputabilidade penal. A interface, entre direito penal e psiquiatria, demarca uma passagem entre um regime estritamente disciplinar para um novo um regime de normalização. ${ }^{2}$ Foucault (2001) destaca que esse poder de normalização não se reduz nem ao poder psiquiátrico nem ao poder jurídico nem à simples composição entre estes dois campos. O discurso da psiquiatria penal não respeita nem às regras científicas da psiquiatria de sua época nem as regras do direito de sua época, configurandose enquanto um discurso que, embora grotesco, tem o poder de verdade e o poder de matar. Trata-se de uma nova modalidade de poder, que se atualiza através do dispositivo do exame e põe em relação diferentes instituições, a saber, a médica e a jurídica. Dito de outro modo, o diagrama não pertence a nenhuma das instituições especificamente, mas responde a um diagrama coextensivo ao todo campo social, que perpassa e redefine os limites da Psiquiatria e do Direito na medida em que responde a uma urgência: normalizar as condutas.

$\mathrm{O}$ discurso do psiquiatra penal, enquanto um discurso de verdade, porque científico, introduz uma nova estratégia jurídica, uma vez que, a partir do laudo, condena-se menos o ato e mais o comportamento, um estilo de vida moralmente condenável. Ao caracterizar o comportamento do sujeito desviante, o dispositivo do laudo psiquiátrico consegue articular a esfera particular da clínica à esfera pública do julgamento criminal, criando um novo regime de visibilidade: os comportamentos desviantes como doença e propensão ao crime. Como afirma 
a sociologia do desviante: “(...) Ele não é apenas um usuário abusivo de crack,

ele sempre está acompanhado de outros desvios comportamentais. Por isso, o comportamento desviante heterogêneo é o retrato sociológico mais expressivo do tipo social do crackeiro" (LIMA, 2016, p. 48).

Outro fator importante apresentado foi a relação tensa que se estabeleceu entre o direito e a medicina nos casos de crimes em que não havia elementos de delírio (grande sintoma da loucura do século XIX), mas que eram caracterizados pela perda de função racional dos sujeitos, sendo que com isso houve uma penetração e uma nova relação entre essas duas áreas de saber.

A resultante dessa relação é que a existência dos delírios deixa de ser a característica necessária para o indicativo do estado de loucura. Em seu lugar, temos a emergência do comportamento impulsivo, ou seja, da relação entre o voluntário e o involuntário e que também pode ser considerada uma alienação, do ponto de vista médico e jurídico. A justiça torna-se cada vez mais terapêutica e a medicina, cada vez mais jurídica. Os comportamentos desviantes se tornam assim alvo de uma discursividade e de uma visibilidade próprias. Esse arcabouço criou as condições para a condenação moral e jurídica uma vez que ganha estatuto de verdade científica.

Essa dominância dos instintos leva a uma desalienação do saber psiquiátrico, que adota o princípio do instinto como substituto do delírio na gênese da loucura e do comportamento desviante. Com esse movimento, a psiquiatria penetra de um modo mais generalizado na sociedade, pois se erige como ciência dos 'anormais' e das condutas 'anormais'. Com isso, o autor firma a análise da passagem da intervenção de um poder em suas manifestações mais repressivas e disciplinares, voltadas majoritariamente para os indivíduos, para um momento no qual as estratégias do governo das populações tomam centralidade, aliadas às estruturas jurídicas e médicas de intervenção.

Fica evidente a relação desse aspecto com a discussão atual, sobre os usuários de drogas no contemporâneo. Destacamos o quanto esses evocam o quadro dos 'anormais', permitindo uma nova investida e expansão desse poder positivo de intervenção sobre as populações, e em especial sobre as populações mais vulneráveis, culminando em sua segregação no contexto brasileiro. Desse modo, os usuários de drogas vão aos poucos constituindo um novo regime de visibilidade agenciado pelos dispositivos jurídico-psiquiátricos. 
No Brasil, a articulação entre criminologia e psiquiatria vem de um diálogo iniciado na segunda metade do século XIX (COSTA, 1981; MACHADO, 1978, RAUTER, 2003). A diferença entre estas duas disciplinas consiste no fato da criminologia surgir no interior do Direito Penal, enquanto a "psiquiatria se insurge do exterior, disputando com o direito penal o papel de gestora do criminoso, através de uma relação, progressivamente mais íntima, entre crime e doença mental" (RAUTER, 2003, p. 41). A psiquiatria garantiu, assim, um novo destino aos que fugiam da norma, "eles não serão excluídos por infração a um código de leis explícito, como o criminoso. Mas ao serem definidos como doentes, sua exclusão justifica-se como tratamento" (RAUTER, 2003, p. 43). Em suma, cria-se uma sobreposição entre estes domínios de modo a estabelecer um enquadramento institucional para os desviantes.

Atentando-se para isso, Merhy (2007) apresenta a percepção de que atualmente percebemos um progresso desse processo de disciplinarização e controle, aliado à hegemonia do discurso medicalizante e a produçōes políticas e subjetivas conservadoras e reacionárias. Segundo o autor, o biopoder se desenvolve de forma a intervir nos processos desejantes dos indivíduos e de coletivos, gerando o que ele chama de "anormais do desejo". Com este artifício, produz-se então uma capacidade definitiva de intervenção. Essa intervenção, relata o autor, inscreve-se na produção subjetiva dos indivíduos e embasa ações de cunho exilar, induzindo a leitura de que certos desejos (e isso se realiza de forma particular com as compulsóes, mas se expande para todas as expressões de consumo cotidianas) são anormais.

$\mathrm{O}$ exercício do poder que agencia o fenômeno das drogas tem dupla complexidade: é um fenômeno social presente na vida, de tal modo que o uso de substâncias lícitas ou ilícitas se torna hábito cotidiano e coextensivo a todo o campo social, e, ao mesmo tempo, produz um corte nessa multiplicidade, tendendo a gerar um discurso unificador a respeito do usuário de drogas, que recai de modo estratégico sobre as populações mais vulneráveis, em sua maioria, pobres e negros, os denominados "ralé" (SOUZA, 2016), ou melhor, outsiders da ralé (LIMA, 2016) ou ralé da ralé (MAYORA, 2016). Dito de outra maneira, foi necessário criar um corte que focalizasse determinadas experiências com as drogas de modo a definir uma verdade sobre as drogas: a rua, a sarjeta e a miséria como foco de visibilidade definidora de uma verdade sobre os riscos do consumo de drogas. 
Avança, doravante, a proposta de atenção em regime fechado, por tempo prolongado e involuntário, pautada no argumento de que os sujeitos alvos dessa ação ou estão à margem da sociedade ou são impossibilitados de se adaptar à vida em sociedade, segundo critérios e padrões estabelecidos. O que esse argumento de não adaptação desconsidera é que não podemos afirmar isso em relação à sociedade de consumo, pois, nesse aspecto, os usuários de substâncias se colocam como engajadíssimos, sejam pelo consumo de substâncias lícitas ou ilícitas.

Percebemos que a crítica está ligada ao aspecto de não adequação desses sujeitos à sociedade do trabalho formal e às suas estruturas de organização. $\mathrm{O}$ usuário de drogas empresário de si e, portanto, engajado da produção e competição, encontra-se fora dos holofotes. Dessa forma, o comportamento se torna desviante quando se torna resistente ou quando nega totalmente o sujeito da disciplina e da ação de produção capitalista, fundamental para o mundo do trabalho e da produção de valor.

Entra em cena, então, o discurso do risco à saúde, em seu viés mais higienista e totalitário, associado ao discurso da ordem urbana, atendendo a parcela da sociedade não usuária, sua maioria - ou que se acredita não usuária e maioria, pois bastaria considerar uso de álcool, cigarro e medicação psicotrópica para que essas parcelas percebessem que têm muito em comum. Tal discurso busca a comoção e o convencimento dessa outra parcela da sociedade, que se vê amedrontada diante desses sujeitos que não partilham os valores do mundo da produtividade competitiva, ou que se encontram em situação de vulnerabilidade por diversos motivos, tão múltiplos quanto suas próprias histórias de vida.

É justamente nesse corte que se destacam algumas experiências com as drogas, operando-se uma unificação da multiplicidade na figura do improdutivo e vagabundo, em que a IC aparece como um dispositivo normalizador, como índice do poder que atrela uma força disciplinar sobre os corpos a um exercício de um poder que se exerce sobre a vida, no sentido de fazer viver, um poder de normalização que se exerce na medida em que se promove a saúde e o bem-estar: um biopoder (FOUCAULT, 2005, 2008)

Para que numa sociedade "que faz viver", a morte, o velho poder soberano de matar, seja justificada, é necessário encontrar no contínuo da espécie um corte, algo que ameace a própria espécie humana. Foi nesse ponto que a noção de raça encontrou um campo de proliferação, uma vez que a partir dela foi possível 
definir que raças são ameaças à espécie humana (FOUCAULT, 2005, 2008). O biopoder não inventou o racismo, mas permitiu atrelá-lo, a partir de teorias criminais e psiquiátricas ao longo do século XX, a um conjunto de práticas voltadas para as raças ditas 'perigosas' e 'degeneradas': negros, latinos, asiáticos. Como analisa Wacquant (2001), estratégia de "tolerância zero" foi fundamental para a estruturação da penalização da miséria através de uma nova estratégia carcerária da população pobre e negra norte-americana. "A prova: os negros representam 13\% dos consumidores de droga e, no entanto, um terço das pessoas detidas e três quartos das pessoas encarceradas por infração à legislação sobre drogas" (Wacquant, 2001, p. 95).

Tal ação se opera também porque ambos os saberes (jurídico e médico) sempre conservaram a relação entre a loucura e a periculosidade do sujeito, não só em relação aos danos ao outro, mas em relação à sua própria vida, o que permite a essa intervenção justificar-se com argumentos amparados na preservação da vida.

Percebemos, também, que tal poder possibilita uma investida estratégica sobre os usuários de crack em situação de rua, porque eles expressam, em seu quadro, uma relação direta com esse imaginário de atentado contra a vida, de periculosidade para os outros e para si, evocando as intervenções dos saberes e poderes agenciados. Por último, aplicam-se as ações de internação e segregação de um grupo populacional - acobertando, através de discursos tecnicistas, sua vocação totalitária -, apoiadas em açōes profiláticas de defesa social contra a "degeneração", as quais representam tais indivíduos notadamente de caráter discriminatório e racista (Wacquant, 2001).

Conforme se articulam esses saberes e poderes, aliados a padrōes de produção de subjetividade, direcionam-se para práticas que, em nome da sociedade, pretendem intervir para normatizar e, se necessário, retirar de circulação esses indivíduos tidos como 'anormais'.

A partir do fenômeno contemporâneo do crack no Brasil, um novo regime de visibilidade e dizibilidade foi adensado, um regime que liga as ditas 'cracolândias' a uma nova rede discursiva psiquiátrica-midiática (WURDIG; MOTTA, 2015; CUNDA; SILVA, 2014), tendo como correlato de tratamento as instituiçôes axilares e como principal abordagem, a IC. Há, portanto, um diagrama que sustenta a formação de discursos grotescos com poder de verdade e de matar: afirmações como "basta usar uma vez para se viciar", "essas pessoas estão na rua 
por conta do uso do crack" ou "o crack é uma droga que mata rapidamente"

passaram a agenciar um regime de verdades sobre os usuários de drogas.

Não pretendemos desconsiderar a sua potencialidade como substância nociva à saúde e com impactos sociais relevantes no cenário urbano brasileiro, entretanto, interessa-nos, também, realizar uma leitura de um possível uso desse aspecto para determinada ação política.

O maior estudo do mundo sobre perfil de usuários de crack demostra que o tempo médio de uso de crack nas capitais do Brasil é de oito anos e nos demais municípios, de cinco anos, indicando que o uso de crack se caracteriza como um problema de saúde crônico, exigindo ações menos emergenciais e mais investimentos em ações longitudinais, como as realizadas pela $A B$, e serviços substitutivos em saúde mental, como os CAPS-AD. Em relação aos CAPS-AD, identificou-se que apenas 6,3\% dos entrevistados tinham acessado este tipo de serviço e que $78,9 \%$ diziam desejar se tratar para o uso de drogas (BASTOS; BERTONI, 2014). Embora científicos, a propagação dessas análises nas mídias é praticamente nula, uma vez que produzem outra visibilidade sobre o uso de crack, que aponta, por sua vez, para um modelo de atenção territorial e longitudinal. E certamente esse novo regime de visibilidade e dizibilidade não teria sido evocado com tanto empenho se não tivesse um alvo preciso: constituir o fenômeno do crack como signo da falência da Reforma Psiquiátrica e oportunidade para reativar um modelo público de atenção asilar, e a partir de um novo agenciamento entre psiquiatria e justiça, reformular as bases legais da saúde mental no Brasil (YASUI, 2013).

Embora não tenha anulado a histórica articulação entre medicina e justiça no controle dos ditos anormais, a RPB produziu uma importante modificação nesta, na medida em que produziu uma nova política pública que propõe novas bases para a articulação entre medicina e justiça.

\section{Dispositivo da Internação Compulsória e o diagrama da Reforma Psiquiátrica Brasileira}

A IC, tomada nesse estudo como um dispositivo, não é, portanto, uma novidade brasileira inventada pela Reforma Psiquiátrica (RP) ou pelas políticas de combate ao uso do crack. Interessa analisar os tipos de relação que se estabelecem entre o dispositivo de IC e diferentes diagramas de saber-poder-subjetividade. Um novo tipo de relação que a IC introduziu a partir do fenômeno 'crack' nas cidades 
brasileiras, em especial, Rio de Janeiro e São Paulo, a partir de iniciativas de IC em massa, foi uma inversão tendenciosa do que propõe a Lei no 10.216/01, que vem sendo utilizada para validar uma prática axilar e contrária ao seu caráter reformista.

De modo geral, podemos situar a RP enquanto um movimento de resistência a uma modalidade de poder de normalização, para a qual a IC sempre cumpriu uma função de identificação dos anormais, e desse modo estabelecer seu diagnóstico, prognóstico, terapêutica e pena. A IC opera o agenciamento entre a Psiquiatria e o Direito Penal como estratégia de pôr em funcionamento um regime de normalização das condutas. Foi em crítica a esse diagrama de normalização que a RP institui um conjunto de dispositivos, entre eles, a Lei da Reforma Psiquiátrica, que tem por finalidade reconstruir um novo diagrama, que passa por uma outra relação entre a loucura e a cidade, através da diretriz da reabilitação psicossocial. Doravante, o dispositivo da IC encontra-se agenciado e condicionado a novos princípios e diretrizes que não eliminam a IC, mas que, no texto da lei que regulamenta a RP, alteram sua função estratégica. A principal alteração estratégica é a mudança de posição da IC, de um lugar de centralidade e prioridade, para um lugar periférico de retaguarda.

Sabe-se que a Lei no 10.2016/01 contém os trâmites utilizados para se realizar a IC de pessoas portadoras de transtornos mentais, inserida no aspecto legal de amparo à Reforma Psiquiátrica Brasileira. ${ }^{3}$ Entretanto, para a RPB, a IC comparece circunscrita por uma política composta por uma série de outros dispositivos, legais e assistenciais, que promovem a desinstituicionalização, conferindo uma função para a IC, bem delimitada. Porém, o que ficou evidente nessa movimentação da internação de usuários de crack e outras drogas foi a utilização do mecanismo de IC desvinculado do contexto da Lei no 10.216/01, de modo a justificar a ação de internação dos usuários de crack, negando os aspectos de salvaguarda dos direitos presentes na lei da reforma proposta, que inclusive regula a internação de pessoas que sofrem de transtornos mentais, uma vez que, segundo a RPB, a IC necessita de laudos individualizados.

No contexto atual da última década, em virtude do "fenômeno do crack" a legislação da RP tem sido utilizada para justificar a internação de usuários de drogas, contrariando a tentativa progressista contida em sua origem. Ocorre, então, o uso de aspectos dessa lei para justificar o procedimento de IC, equiparando-se o usuário de drogas a um portador de transtorno mental grave, baseado em laudo médico que ateste tal situação clínica, cabendo ao juiz, posteriormente, a decisão. 
Porém, contestações dessa leitura jurídica têm surgido em razão da sua aplicação por analogia. Isso resulta em restrição de direitos básicos e que, em certo ponto, ferem o atual Estado Democrático de Direito, conforme indicam Souza e Silva (2014).

O debate da internação, inclusive, permeia tal estruturação de rede através da proposta de ampliação dos CAPS-AD III, que conta com leitos e funcionamento 24 horas. Nesses serviços, as experiências de espaço protegido, internação e intervenção da equipe, não aparecem afastadas das características territoriais e da implicação do usuário, bem como de uma lógica atrelada a projetos de cuidado individualizados. Assim, a internação de curta duração se configura como estratégia terapêutica ofertada aos usuários dos CAPS-AD, através de um processo de pactuação atrelado ao cuidado em Saúde Mental.

Não há como negar a contradição presente nessa complexa situação social. Destaca-se um artigo da lei reformista e utiliza-se como um dos componentes do mecanismo de produção de uma prática sobre as populações e atenção a sua saúde, calcada não nos preceitos da Reforma Psiquiátrica, mas nos preceitos do higienismo, não nos termos da reabilitação, mas nos da exclusão. As "cracolândias", enquanto uma produção social, trouxeram novos desafios para a Reforma Psiquiátrica, levando-a ao seu limite, sendo neste ponto questionada estrategicamente como um paradigma ineficiente para lidar com essa nova situação, questionamento este que não se converte em investimento e produção de novos dispositivos e estratégias de cuidado à Saúde Mental das populações, mas em uma tentativa de retrocesso e desvalorização da Atenção Psicossocial (YASUI, 2013).

Tal percepção nos leva a questionar quais os efeitos desse retrocesso nas políticas reformistas de saúde mental e o que essa prática revela, atualmente, sobre os movimentos da sociedade brasileira. Se a RP conseguiu, em grande medida, alterar a função estratégica da IC nos casos de pessoas com transtorno mental, a produção social do fenômeno crack reinseriu esse dispositivo como elemento central e agenciador de um regime de normalização jurídico-psiquiátrico. Dessa forma, percebemos o investimento em um processo contrário às perspectivas da Atenção Psicossocial e da Reforma Psiquiátrica Brasileira, principalmente no que concerne às populações em situação de vulnerabilidade, como as que vivem na rua, em que se considera que a Internação Compulsória é uma reparação dos fracassos do Estado e das Políticas de Saúde. 
Em relação às Redes de Atenção, o impacto reside não só num possível desinvestimento em outras perspectivas de atenção, mas na abordagem restrita que a internação impõe aos serviços de atenção em regime aberto, resultando-se, assim, em processos de porta giratória infindável - já vividos em outros momentos da atenção psiquiátrica em nosso país.

Tal percepção nos permite pensar que o tratamento ligado ao uso de drogas deve abarcar aspectos psicossociais importantes, sendo que a proposta de internação em massa, longe de responder só à fantasia de tratamento infalível, responde também à demanda social sobre a retirada desses sujeitos de circulação nas cidades. Opera-se, desse modo, uma passagem sutil, mas poderosa em seus efeitos, da IC em massa para a massificação da IC.

$\mathrm{O}$ fracasso das medidas de IC em massa que foram utilizadas principalmente no eixo Rio-São Paulo durante os anos de 2011, 2012 e 2013 (RUI, 2012; MACERATA; DIAS; PASSOS, 2014) e que agora retornam no governo de Doria em São Paulo, ${ }^{4}$ foi aos poucos legitimando essa outra medida, a da massificação dos pedidos de IC como estratégia a ser articulada pelos CAPS-AD, mediante uma ação judicial respaldada por um laudo médico. A estratégia de um poder que se apoia e se fortalece justamente no fracasso foi muito bem apresentada por Foucault (1977), sobre o aparente fracasso das prisões em relação aos objetivos de reinserção social. (DREYFUS; RABINOW, 2010).

Do fracasso da IC em massa como medida de tratamento eficaz, foi possível extrair uma estratégia muito mais capilar, extensiva e permanente de normalização: a massificação da IC. Desse modo, os CAPS-AD passam gradativamente a ser inseridos em um novo agenciamento, no diagrama de normalização médicojurídico, que faz dos CAPS-AD não mais as portas de entrada, mas sim os meios de passagem para internações psiquiátricas mediante um mandato judicial pautado num laudo médico, que, embora exterior ao próprio serviço, exerce um tipo de poder que subordina a equipe do CAPS-AD, inclusive o próprio médico.

\section{Conclusão}

Com sua origem enquanto movimento social e o decorrente processo histórico de se constituir enquanto política de Atenção à Saúde Mental vigente no Brasil, a Reforma Psiquiátrica apresenta dimensōes teórico-conceituais, político-jurídicas, técnico-assistenciais e socioculturais. 
A desinstitucionalização pode ser considerada em sua dimensão sociocultural, na medida em que tenta deslocar a predominância do discurso técnico de intervenção (médico, psiquiátrico, jurídico) sobre a loucura para outros campos do meio social, objetivando-se uma transformação do imaginário social sobre o sujeito louco e sobre a doença mental, em uma tentativa de produzir outros sentidos sociais comuns, além do que foi construído historicamente.

Também na dimensão teórico-conceitual, percebemos a importância dos aspectos referentes ao processo de des-hospitalização dos modelos assistenciais, com propostas de atenção em regime aberto, a desconstrução de práticas calcadas em isolamento, tutela e limitação da autonomia das pessoas que vivenciam transtornos mentais.

É evidente que esses aspectos têm grande importância para a continuidade dos processos progressistas de atenção à Saúde Mental, sendo importantes para o movimento, uma vez que pretendem abrir campos de produção de discursos e práticas que façam frente aos poderes, que sempre tiveram a dominância sobre o fenômeno histórico da loucura.

Não é de se estranhar, também, que seja esse um dos pontos em que tais poderes concentrarão o investimento e as tentativas de desconstrução desse discurso democrático, objetivando novas formas de se legitimar e se aplicar na atualidade, com a mesma intensidade aplicada em outros momentos. Sendo assim, o poder psiquiátrico se agencia ao poder jurídico, no dispositivo da IC, buscando um fortalecimento diante do contraponto reformista vigente.

Conforme o movimento da Reforma Psiquiátrica avança, percebe-se que se articulam forças de resistência a sua expansão e legitimação, bem como novas formas de tensões sociais se posicionam. Dentro desse panorama, as relaçôes dos poderes médico e jurídico, com sua constante atualização e busca por expansão de ação no social, propõem formas de intervenção e práticas em que possam recuperar a sua centralidade hegemônica, como é no caso da IC, que garante também a produção de discursos técnicos que permitam recuperar o protagonismo histórico e político de abordagem e controle das populações.

Consideramos que este momento de contexto do uso e ampliação do discurso e da intervenção da IC configura uma expressão desse movimento, não só como resistência ao processo de desinstitucionalização em curso, mas também como forma de potencializar as intervenções de inspiração conservadora ou retrógrada, valendo-se da ação sobre os tidos como anormais, agora, os usuários de drogas 
e avivando-se, consequentemente, esses dispositivos de poder na produção subjetiva contemporânea.

Além disso, foi possível perceber que existem também elementos desse discurso que podem nos guiar, em relação a uma reflexão sobre o quanto as práticas de IC têm efeitos de que são novas experiências de institucionalização, que se inscrevem na experiência social em formatos mais sutis, uma vez que não são diretamente reconhecidas pelos sujeitos nem definitivas em sua história de vida, e, até por isso, expressões bem-sucedidas de ação do biopoder.

Com a intensificação da judicialização dos processos de internação de pessoas em uso de drogas, percebemos essa emergência de fenômenos de institucionalização que unem perspectivas clássicas de iatrogenias já conhecidas a novos impactos e aprisionamentos da produção de políticas e de subjetividades contemporâneas, com grande impacto na Reforma Psiquiátrica Brasileira. ${ }^{5}$

\section{Referências}

AZENHA, S.S.D. O internamento compulsivo e a representação da doença mental: percurso histórico. Arquivo de Medicina. Porto, v. 28, n. 2, p. 54-60, abr. 2014. Disponível em: <http://www.scielo.mec.pt/pdf/am/v28n2/v28n2a05.pdf>. Acesso em: 23 set. 2015.

BASTOS, F.; BERTONI, N. Pesquisa nacional sobre o uso de crack. Quem são os usuários de crack e/ou similares do Brasil? Quantos são nas capitais brasileiras? Rio de Janeiro: Lis/ Icict/Fiocruz, 2014.

BATISTA, V.M. Drogas e criminalização da juventude pobre. In: Associação Beneficente São Martinho (Org.). No mundo da rua. Rio de Janeiro: Casa da Palavra, 2001, p. 44-56.

BRASIL. Lei no 10.216, de 6 de abril de 2001. Dispõe sobre a proteção e os direitos das pessoas portadoras de transtornos mentais e redireciona o modelo assistencial em saúde mental. In: BRASIL. Ministério da Saúde. Secretaria de Atenção à Saúde. SVS/CN-DST/AIDS. A Política do Ministério da Saúde para Atenção Integral a Usuários de Álcool e outras Drogas. 2. ed. rev. ampl. Brasília: Ministério da Saúde, 2004 (Série B. Textos Básicos de Saúde).

BRITTO, R.C. A internação psiquiátrica involuntária e a Lei 10.216/01. Reflexóes acerca da garantia de proteção aos direitos da pessoa com transtorno mental. 2004. 210 folhas. Dissertação (Mestrado em Saúde Pública) - Fundação Oswaldo Cruz, Escola Nacional de Saúde Pública, Rio de Janeiro, 2004.

COSTA, J.F. História da Psiquiatria no Brasil. Um corte ideológico. Rio de Janeiro: Campus, 1981.

CUNDA, M.F.; SILVA, R.A.N. da. O crack em um cenário empedrado: articulaçōes entre os discursos jurídico, médico e midiático. Psicologia \& Sociedade. Belo Horizonte, v. 26, n. 
spe, p. 245-255, 2014. Disponível em: <http://www.scielo.br/pdf/psoc/v26nspe/25.pdf>.

Acesso em: 24 jun. 2015.

DELEUZE, Gilles. Foucault. São Paulo: Brasiliense, 1988.

O que é um dispositivo? O mistério de Ariana. Lisboa: Veja - Passagens, 1996.

DUAILIBI, L.M.F.B. Revisão sistemática: Perfil dos usuários de cocaína e crack no Brasil. 2010. 86 folhas. Tese (Mestrado) - Programa de Pós-graduação em Psiquiatria, Escola Paulista de Medicina, Universidade Federal de São Paulo, 2010.

DREYFUS, H.L.; RABINOWR, P. Michel Foucault: uma trajetória filosófica. Rio de Janeiro: Ed. Forense Universitária, 2010.

FOUCAULT, M. Vigiar e punir. Petrópolis: Ed. Vozes, 1977.

Os Anormais. Curso no Collège de France (1974-1975). Trad. bras. Eduardo Brandão. São Paulo: Martins Fontes, 2001.

- A verdade e as formas jurídicas. Trad. bras. Roberto Cabral de Melo Machado e Eduardo Jardim Morais. Rio de Janeiro: Nau, 2002.

. Em defesa da sociedade. São Paulo: Editora Martins Fontes, 2005.

. Nascimento da Biopolítica. São Paulo: Editora Martins Fontes, 2008.

HARDT, M.; NEGRI, A. Multidão. Rio de Janeiro: Record, 2005.

LIMA, ALM. A miséria moral da ralé. In: SOUZA, J. (Org.) Crack e exclusão social. Brasília: Ministério da Justiça e Cidadania, 2016, p. 39-74.

LABROUSSE, A. Geopolitica das drogas. São Paulo. Desatino, 2010.

MACERATA, I.; DIAS, R.; PASSOS, E. Paradigma da Guerra às Drogas, Políticas de Ordem e Experiências de Cuidado na Cidade dos Mega-Eventos. In: BATISTA, V. M.; LOPES, L. E. (Orgs.). Atendendo na Guerra: Dilemas Médicos e Jurídicos sobre o "CRACK”. Rio de Janeiro: Revan, 2014. (Criminologia de Cordel 3).

MACHADO, R. Danação da norma: Medicina Social e constituição da Psiquiatria no Brasil. Rio de Janeiro: Ed. Graal, 1978.

MAYORA, M. O crack e a rua. In: SOUZA, J. (Org.) Crack e exclusão social. Brasília: Ministério da Justiça e Cidadania, 2016, p. 137-162.

MERHY, E. E. Saúde: a cartografia do trabalho vivo. São Paulo: Hucitec, 2007.

NEGRI, A.; COCCO, G. Biopoder e luta numa América Latina Globalizada. Rio de Janeiro; São Paulo: Record, 2005.

PASSOS, E. H.; SOUZA, T. de P. Redução de danos e saúde pública: construções alternativas à política global de "guerra às drogas". Psicol. Soc. Florianópolis, v. 23, n. 1, p. 154-162, abr. 2011. Disponível em: <http://www.scielo.br/scielo.php?script=sci arttext\&pid=S0102-71822011000100017\&lng=en\&nrm=iso >. Acesso em: 14 set. 2016. 
RAUTER, C. Criminologia e Subjetividade. Rio de Janeiro: Revan, 2003.

RODRIGUES, T. Narcotráfico e militarização nas Américas: vício de guerra. Contexto Internacional. Rio de Janeiro, v. 34, n. 1, p. 9-41, jun. 2012. Disponível em: <http://www. scielo.br/pdf/cint/v34n1/v34n1a01.pdf>. Acesso em: 18 set. 2015.

RUI, T. Corpos abjetos: etnografia em cenários de uso e comércio de crack. 2012. 335 folhas. Tese (Doutorado em Antropologia Social) - Instituto de Filosofia e Ciências Humanas, Universidade Estadual de Campinas, Campinas, São Paulo, 2012.

SOUZA, S. C. de; SILVA, C. K. A Internação Compulsória de Dependentes Químicos: A prática sob a ótica da Nova Ordem Constitucional. Letras Jurídicas. Belo Horizonte, v. 2, 17 set. 2014. Disponível em: <http://npa.newtonpaiva.br/letrasjuridicas/?p=490>. Acesso em: 23 out. 2014.

SOUZA, T. de P. A norma da abstinência e o dispositivo "drogas": direitos universais em territórios marginais de produção de saúde (perspectivas da redução de danos). 2013. 355 folhas. Tese (Doutorado em Saúde Coletiva) - Programa de Pós-graduação em Saúde Coletiva, Faculdade de Ciências Médicas, Universidade Estadual de Campinas, Campinas, São Paulo, 2013.

- O nascimento da biopolítica das drogas e a arte liberal de governar. Fractal, Revista de Psicologia. Rio de Janeiro, v. 26, n. 3, p. 979-998, set./dez. 2014.

SOUZA, T. de P. e CARVALHO, S.R. Reduzindo danos e ampliando a clínica: desafios para a garantia do acesso universal e confrontos com a internação compulsória. Revista Polis e Psique, v. 2, número temático, p. 37-58, 2012.

SOUZA, J. A doença da humilhação. In: SOUZA, J. (Org.). Crack e exclusão social. Brasília: Ministério da Justiça e Cidadania, 2016, p. 29-38.

TEDESCO, S.; SOUZA, T. de P. Territórios da Clínica: redução de danos e os novos percursos éticos para a clínica das drogas. In: CARVALHO, S.R.; FERIGATO, S.; BARROS, M.E.. (Orgs.). Conexôes: Saúde Coletiva e Políticas de Subjetividade. São Paulo: Ed. Hucitec, 2009, p. 141-156.

WACQUANT, L. As Prisões da Miséria. Rio de Janeiro, Jorge Zahar Editor, 2001. 174 páginas.

WURDIG, K.K.; MOTTA, R.F. Representações midiáticas da internação compulsória de usuários de drogas. Temas em psicologia. Ribeirão Preto, v. 22, n. 2, dez. 2014. Disponível em: <http://pepsic.bvsalud.org/pdf/tp/v22n2/v22n2a14.pdf>. Acesso em: 25 set. 2015. YASUI, S. Reforma e Contrareforma: reflexões em torno da internação compulsória e comunidades terapêuticas. In: JORGE, M.S.B. et al. (Orgs.). Olhares plurais sobre o fenômeno do crack. Fortaleza: EdUECE, 2013, p. 87-104. 
${ }^{1}$ A esse respeito, vide documentos internacionais elaborados pela Comissão Global de Políticas sobre Drogas, trazendo críticas referentes às estratégias atuais de ação e as propostas alternativas sugeridas na Sessão Especial da Assembleia Geral das Naçóes Unidas, realizada este ano. Disponíveis em: <https://www.unodc.org/lpo-brazil/pt/frontpage/2016/06/politicas-sobre-drogas-e-o-desenvolvimento-sustentavel-e-tema-de-nota-tecnica-do-UNODC.html> https://www.unodc.org/lpo-brazil/pt/ drogas/relatorio-mundial-sobre-drogas.html>.

${ }^{2}$ O curso do Collège de France (1974-1975) intitulado "Os Anormais" ocorre um ano antes do curso intitulado "Em Defesa da Sociedade", em que apresenta o conceito de biopoder, um poder a um só tempo individualizante e massificante, regulação da população e docilização dos corpos. Entretanto, observa-se que a noção de normalização aparece como uma passagem conceitual de um poder estritamente disciplinar para uma nova modalidade de poder.

${ }^{3}$ Art. $6^{\circ}$. A internação psiquiátrica somente será realizada mediante laudo médico circunstanciado que caracterize os seus motivos. Parágrafo único. São considerados os seguintes tipos de internação psiquiátrica: I - internação voluntária: aquela que se dá com o consentimento do usuário; II - internação involuntária: aquela que se dá sem o consentimento do usuário e a pedido de terceiro; e III - internação compulsória: aquela determinada pela Justiça.

${ }^{4}$ Disponível em: <http://g1.globo.com/sao-paulo/noticia/doria-diz-que-cracolandia-vai-acabar-antes-do-fim-do-seu-mandato.ghtml>.

${ }^{5}$ A.O. Azevedo realizou a construção teórica e debate, argumentação e redação final. T.P. Souza realizou a construção teórica e debate, orientação, revisão teórica e metodológica, indicação bibliográfica. 


\section{Compulsory Hospitalization of people in drug use and the Brazilian Psychiatric Counter- Reformation}

This article develops a critical reflection to the current motion linked to the Compulsory Hospitalization $(\mathrm{CH})$ initiatives, as an approach and treatment proposal for the people in drugs use, in a context of the new challenges that arise facing the continuity of the Brazilian Psychiatric Reform (BPR). We analyzed the $\mathrm{CH}$ device while visibility regimen producer, perceiving that its practice and legitimation along the cocaine crack user population is associated to elements of historical motions updating, present since XIX century, as presented by Foucault. These motions of articulation among the medical and legal powers produce practices that legitimate itself, by the appropriation of this population as the new Abnormal subject over whom it is intended to intervene. This maneuver also opens breaches for the utilization of mechanisms referring to the $\mathrm{CH}$ present in the BPR law non linked to the other terms, mainly those which are targeting to preserve and sustain the people's rights who are covered and assisted by the Mental Health politics, and uphold the rights of people who are assisted by mental health policies, counteracting the progressive aspects belonging to its origin. We consider the initiatives of $\mathrm{CH}$ processes intensification, action expressions of the biopower, with relevance in the production of politics and contemporary subjectivities of resistance against the continuation and expansion of the Brazilian Psychiatric Reform (BPR).

> Keywords: mental health; compulsory hospitalization; mental health services; Brazilian Psychiatric Reform. 